\title{
FREQUENCY AND FACTORS OF NON-COMPLIANCE AMONG EPILEPTIC PATIENTS
}

\author{
Atifa Gilani, Khurram Haq Nawaz, Zahid Hassan, Muhammad Ali Yousaf, Asif Hashmat, Saeed Arif \\ Pak Emirates Military Hospital/National University of Medical Sciences (NUMS) Rawalpindi Pakistan
}

\begin{abstract}
Objective: To determine the frequency of non-compliance among the patients of epilepsy and factors related to the presence of non-compliance at a tertiary care hospital of Pakistan.

Study Design: Cross-sectional analytical study.

Place and Duration of Study: Neurology department, Pak Emirates Military Hospital Rawalpindi, form Dec 2018 to Jun 2019. Methodology: A total of 133 cases were included in the study, which were diagnosed as epilepsy for more than 6 months by a consultant neurologist. Medication and drug adherence was assessed by validated Urdu version of our-item Morisky Medication Adherence Scale. Relationship of age, gender, socio-economic class, duration of epilepsy, education, marital status and poly-pharmacy was assessed with the presence of non-compliance among the patients suffering from epilepsy.

Results: There were 53 (39.9\%) patients were females while 80 (60.1\%) were males. Out of 118 patients of epilepsy, 59 (44.4\%) showed the presence of non-compliance while 74 (55.6\%) had good compliance. After applying the logistic regression we found that duration of illness and poly-pharmacy had significant association with the presence of non-compliance among the patients of epilepsy.

Conclusion: Non-compliance emerged as a highly prevalent behavior or clinical condition among the patients of epilepsy in our target population. Before combining the pharmacological agents it is advisable to check the compliance of already prescribed drugs used to control the seizures. Patients with long standing illness or those who are put on multiple medications should be regularly screened for non-adherence.
\end{abstract}

Keywords: Epilepsy, Non-compliance, Socio-demographic factors.

This is an Open Access article distributed under the terms of the Creative Commons Attribution License (https://creativecommons.org/licenses/by-nc/4.0/), which permits unrestricted use, distribution, and reproduction in any medium, provided the original work is properly cited.

\section{INTRODUCTION}

Neurological diseases like epilepsy have been underdiagnosed and still remain a stigma in our part of the world compelling WHO to make it part of mental health gap program for third world countries including Pakistan ${ }^{1,2}$. Though diagnosed more commonly and easily as compared to developing countries still burden of illness remain high (2\%) even in the developed countries ${ }^{3}$. It is primarily a seizure disorder but associated with many other mental and physical health problems making it a complex multisystem disorder which demands management strategies more than just prescribing a routine anti-epileptic drug 4,5 .

Non-compliance is a common phenomenon practiced by a large number of patients among all the cultures $^{6}$. Non-compliance is counter therapeutic and associated with greater relapse rate and increased incidence of the complications related to the underlying illness ${ }^{7}$. This issue is prevalent in developed as well as low and middle income countries ${ }^{8}$.

Epilepsy is a fairly common neurological disease affecting all the age groups of the population. Once diagnosed, patient may require the medication for a

Correspondence: Dr Atifa Gilani, Resident Neurologist, Pak Emirates Military Hospital, Rawalpindi Pakistan

Received: 25 Jul 2019; revised received: 07 Feb 2020; accepted: 28 Apr 2020 long period. Results of study conducted by Getnet et al, summarized that around $37 \%$ of the epileptic individuals in US were non adherent to the prescribed medication ${ }^{9}$. Anotherstudy done by Gurumurthy et al, in 2017 on the patients with epilepsy generated similar results and socioeconomic status and health education were significantly linked with the noncompliance among the target population ${ }^{10}$. A recent systematic review concluded that medication adherence among the epileptics was poor world-wide and use of complementary medicine was a common practice. Non-compliance can lead to increased frequency of breakthrough seizures among the epileptics making them prone to all the life threatening complications related to seizures in addition to the poor quality of life and psychological stress.

Multiple factors can be linked with the phenomenon of non-compliance and poor adherence to prescribed medication among the patients suffering from chronic illnesses. Patient related factors, illness related factors, treatment related factors, clinician related factor and environmental and cultural factors are the few broad categories which encompass numerous causes linked with the non-compliance among the patients. Physicians must keep in mind the high prevalence of this problem and factors related to it in order to identify and counter it effectively. 
Non compliance or poor adherence to prescribed medications has been a less discussed topic in studies done in our part of the world. These studies usually cover the routine epidemiological facts regarding epilepsy ${ }^{10}$. Low and middle income countries focus on primary and secondary prevention in order to reduce the health budget and improving compliance is a big part of that strategy but no study has so far been done in our patients to look for this aspect. This study was planned with the objective to assess the prevalence of non-compliance among the patients of epilepsy and analyze the factors associated with this phenomenon among these patients.

\section{METHODOLOGY}

This cross-sectional study was conducted at the department of Neurology, Pak Emirates Military Hospital Rawalpindi, from December 2018 to June 2019. Sample size was calculated by WHO Sample Size Calculator by using population proportion prevalence of $88.5 \%{ }^{6}$. Non probability consecutive sampling technique was used to gather the sample. All patients between the age of 18 and 60 with epilepsy diagnosed by a consultant neurologist according to 2010 International League Against Epilepsy (ILAE) Commission report were included in the study. Exclusion criteria were the patients with psychogenic non epileptic fits, head injury, mental retardation or learning disability, dystonias and psychiatric disorders. Patients who were pregnant orbreast feeding, had B-12 or folate deficiency, had recent surgery, or any autoimmune disorder, those who were using illicit drugs or those whose follow up was not possiblewere also excluded from the study. Patients with evidence of cognitive impairment or dementia or delirium were also declared as part of the exclusion criteria.

Ethical review board committee of the hospital was approached to get the ethical approval for this study. Written informed consent was taken from all the potential participants of this study before the start of study after complete description of the study. Socio demographic variables were also collected. Variables in the study included age, gender, socio-economic class, duration of epilepsy, education, marital status and poly-pharmacy. Duration of illness was classed as disease lasting for less than or more than five years. Use of more than one drug for epilepsy was regarded as poly-pharmacy. Matriculation was used as cut-off education for this study. Socioeconomic class was classed as $\geq$ regular expenditure. It was based on a regular economic survey done in Pakistan. Confounding variables were identified and adjusted by detailed history taking, examination and review of all the old documents possessed by the patient. Validated Urdu version of four-item Morisky Medication Adherence Scale was used in the study to assess the presence of non-compliance among the study participants ${ }^{18}$. The score of each item was added to give a range of scores from $0-4$. A score of $>2$ suggests that the patient is adherent, while a score of $\leq 2$ suggested that the patient was non-adherent.

Characteristics of participants and the distribution of the compliance to medication were described by using the descriptive statistics. Participants were resulted by categorical compared by compliance and noncompliance. Chi-square was used to determine between-group variances in categorical correlates. All statistical analysis was performed using SPSS-24. Differences between groups were considered significant if $p$-values were $\leq 0.05$.

\section{RESULTS}

A total of 146 patients were enrolled to participate in this study. Three did not give consent. Four had psychogenic non epileptic seizures. Five had psychiatric illness or co morbid illicit substance use. Therefore total 133 patients were included in the final analysis. Eighty $(60.1 \%)$ were males and $53(39.9 \%)$ were females patients. Out of 133 patients of epilepsy, 74 (55.6\%) showed the presence of good compliance while 59 $(44.4 \%)$ had the presence of non-compliance towards the prescribed medication. Longer duration of illness and poly-pharmacy were linked with the presence of non-compliance when chi-square was applied.

\section{DISCUSSION}

This study incorporated one chronic medical condition and response of the patient on the pharmacological treatment regarding that illness. Non-compliance to epilepsyis not a new topic for the west and developed countries started looking for quantifying this phenomenon in the form of research in order to get the exact data on this aspect of epilepsy management ${ }^{12,13}$. Using the routine self-reporting method, around $44.4 \%$ of our participants showed the presence of non-compliance and that included the patients of both genders of adult age group. Use of more than one AED, having breakthrough seizures despite treatment or daily life stressors may be the factors leading to poor adherence in our target population ${ }^{13,14}$. Reason behind these might be related to adverse effect of medication or desired effects less than the expectations of the patient. Our sample population comprised of patients of a develo- 
ping country which have a lot of confounding variable predisposing them to non-adherence of the medication especially for the long standing illnesses. Non-compliance has always been linked with disease relapse and poor overall quality of life 14 of the patient and efforts have been made to improve this aspect of health care.

Table-I: Characteristics of the study group and their compliance status.

\begin{tabular}{|c|c|c|c|}
\hline $\begin{array}{l}\text { Socio } \\
\text { Demographic } \\
\text { Factors } \\
\text { Total }\end{array}$ & $\begin{array}{c}\text { Good } \\
\text { Compliance } \\
\mathbf{n}(\%) \\
74(55.6) \\
\end{array}$ & $\begin{array}{c}\text { Poor } \\
\text { Compliance } \\
n(\%) \\
59(44.4) \\
\end{array}$ & $\begin{array}{c}p \text { - } \\
\text { value }\end{array}$ \\
\hline \multicolumn{4}{|l|}{ Age } \\
\hline $\begin{array}{l}<30 \text { year } \\
30-60\end{array}$ & $\begin{array}{l}31(41.5) \\
43(58.5)\end{array}$ & $\begin{array}{l}24(39.6) \\
35(60.4)\end{array}$ & 0.888 \\
\hline \multicolumn{4}{|l|}{ Gender } \\
\hline $\begin{array}{l}\text { Male } \\
\text { Female }\end{array}$ & $\begin{array}{l}42(46.1) \\
32(53.9)\end{array}$ & $\begin{array}{l}21(35.8) \\
38(64.2)\end{array}$ & 0.372 \\
\hline \multicolumn{4}{|l|}{ Education } \\
\hline $\begin{array}{l}<10 \text { years } \\
\geq 10 \text { years }\end{array}$ & $\begin{array}{l}55(75.4) \\
19(24.6) \\
\end{array}$ & $\begin{array}{l}42(71.7) \\
17(28.3) \\
\end{array}$ & 0.686 \\
\hline \multicolumn{4}{|l|}{ Poly-Pharmacy } \\
\hline $\begin{array}{l}\text { No } \\
\text { Yes }\end{array}$ & $\begin{array}{l}39(53.9) \\
35(46.1)\end{array}$ & $\begin{array}{l}15(26.4) \\
44(73.6)\end{array}$ & 0.001 \\
\hline \multicolumn{4}{|c|}{ Duration of Illness } \\
\hline $\begin{array}{l}<5 \text { years } \\
\geq 5 \text { years }\end{array}$ & $\begin{array}{c}71(95.4) \\
03(4.6) \\
\end{array}$ & $\begin{array}{l}40(66.1) \\
19(33.9)\end{array}$ & $<0.001$ \\
\hline \multicolumn{4}{|l|}{ Marital Status } \\
\hline $\begin{array}{l}\text { Married } \\
\text { Single }\end{array}$ & $\begin{array}{c}49(95.4) \\
25(4.6)\end{array}$ & $\begin{array}{c}34(95.4) \\
25(4.6)\end{array}$ & 0.310 \\
\hline \multicolumn{4}{|c|}{ Socio Economic Status } \\
\hline $\begin{array}{l}<\text { Outgoing } \\
\geq \text { Outgoing }\end{array}$ & $\begin{array}{c}59(95.4) \\
15(4.6)\end{array}$ & $\begin{array}{l}44(95.4) \\
15(4.6)\end{array}$ & 0.481 \\
\hline
\end{tabular}

Various methods have been used in various cultures to look for the compliance. Measuring the drug levels in serum is one but it is very expensive and laboratory methods to measure all the epileptic drugs have not been available in our country. Therefore we used the self-rating simple scale which has been used effectively in the past in various local and foreign studies $^{12,18}$. Multiple studies in the past have studied various factor linked with the poor compliance of medication in various chronic illnesses. We chose a set of factors based upon these studies as well as incorporating our own experience of patients as sociocultural and religious factors in our populations have been very different from the west. Ideally a qualitative study has been the right answer to this problem.

Siddiqui et al, in their study in Pakistani population concluded that most of the patients recruited in the study were males ${ }^{16}$. Results of our study in 2019 were not different from their results and still male population dominated the sample. As sample population was derived from the patients reporting to a military hospital so results could not be generalized regarding the gender of patients. Gender was also not linked to non-compliance in our analysis upon application of the relevant statistical test.

Most of the anti-epileptic drugs have a lot of untoward effects which sometimes force the patients to stop these on their own or skip the doses. It is understandable and also reported in the literature by Moura et al, that using multiple medications for control of seizures in an epileptic patient result in non-adherence and management strategy of combining the AEDs eventually becomes counter theraputic ${ }^{19,20}$. This association was supported by our study analysis and polypharmacy emerged as strong predictor of non-compliance among the epileptic patients.

Long duration of illness is usually associated with physical and psychological consequences. Our study results revealed that patients with long duration of illness had more chance of developing the non-compliance as compared to patients with less duration of illness. Studies by Getnet et al, and Moura et al, in 2016 in have also produced similar results. Longer duration of illness whether treated or untreated can have direct and indirect effects on the body which can give rise to various problems including the compliance ${ }^{9,20}$.

\section{LIMITATION OF STUDY}

Randomized selection of study subjects from all the epileptic patients was not done. It lacked the generalizability as epileptic patients of one department were included in the study instead of patients from all over the country. Self-rating compliance scale also pose issues as the study participants may intentionally under rate or over rate the symptoms on the self-rating scale. Drug levels if included in the study design and carried out for the patients may have revealed more precise results regarding the compliance and drug adherence. These limitations could be started for in the future studies with larger sample size and sophisticated study design.

\section{CONCLUSION}

Non compliance emerged as a highly prevalent behavior or clinical condition among the patients of epilepsy in our target population. Before combining the pharmacological agents it is advisable to check the compliance of already prescribed drugs used to control the seizures. Patients with ling standing illness or those who are put on multiple medications should be regularly sceened for non-adherence. 


\section{CONFLICT OF INTEREST}

This study has no conflict of interest to be declared by any author.

\section{REFERENCES}

1. World Health Organization \& UNHCR. Mh GAP Humanitarian Intervention Guide (mhGAP-HIG): clinical management of mental, neurological and substance use conditions in humanitarian emergencies. WHO: Geneva (2015).

2. Humayun A, Haq I, Khan FR, Azad N, Khan MM, Weissbecker I. Implementing mhGAP training to strengthen existing services for an internally displaced population in Pakistan. Global Mental Health 2017; 4(1): e6-9.

3. Yousefichaijan P, Eghbali A, Rafeie M, Sharafkhah M, Zolfi M, Firouzifar $\mathrm{M}$. The relationship between iron deficiency anemia and simple febrile convulsion in children. J Pediatric Neuroscie 2014; 9(2): 110-14.

4. Naseer MR, Patra KC. Correlation of serum iron and serum calcium levels in children with febrile seizures. Int J Contemp Pediatr 2015; 2(1): 406-10.

5. Amudhan S, Gururaj G, Satishchandra P. Epilepsy in India II: Impact, burden, and need for a multisectoral public health response. Ann Indian Acad Neurol 2015; 18(4): 369-81.

6. Addo B, Sencherey S, Babayara MNK. Medication non compliance among patients with chronic diseases attending a primary health facility in a periurban district in Ghana. Int J Chronic Dis 2018; 2018(4): 7187284-88.

7. Cutler RL, Fernandez-Llimos F, Frommer M, Benrimoj C, GarciaCardenas V. Economic impact of medication non-adherence by disease groups: a systematic review. BMJ Open 2018; 8(1): e016982-85.

8. Adidja NM, Agbor VN, Aminde JA, Ngwasiri CA, Ngu KB, Aminde LN. Non-adherence to antihypertensive pharmaco-therapy in Buea, Cameroon: a cross-sectional community-based study. BMC Cardiovasc Disord 2018; 18(1): 150-53.

9. Getnet A, Woldeyohannes SM, Bekana L. Antiepileptic drug non adherence and its predictors among people with epilepsy. Behav Neurol 2016; 2016(1): 3189108-10.

10. Gurumurthy R, Chanda K, Sarma G. An evaluation of factors affecting adherence to antiepileptic drugs in patients with epilepsy: a cross-sectional study. Singapore Med J 2017; 58(2): 98-102.

11. Farrukh MJ, Makmor-Bakry M, Hatah E, Tan HJ. Use of complementary and alternative medicine and adherence to anti epileptic drug therapy among epilepsy patients: a systematic review. Patient Prefer Adherence 2018; 12(1): 2111-21.

12. Kuzmanova R, Stefanova I, Stambolieva K. Significance of non compliance when treating patients with epilepsy. Neurol Neurochir Pol 2018; 52(2): 215-21.

13. Abdellaoui R, Foulquié $P$, Texier N, Faviez C, Burgun A, Schück S. Detection of cases of noncompliance to drug treatment in patient forum posts: topic model approach. J Med Internet Res 2018; 20(3): e85-88.

14. Rao KN, George J, Sudarshan CY. Treatment comp-liance and noncompliance in psychoses. Ind J Psychiatr 2017; 59(1): 69-76.

15. Ullah S, Ali N, Khan A, Ali S, Nazish HR. The Epidemiological characteristics of epilepsy in the province of Khyber Pakhtunkhwa, Pakistan. Front Neurol 2018; 9(3): 845-49.

16. Siddiqui F, Sultan T, Mustafa S, Siddiqui S, Ali S, Malik A, et al. Epilepsy in Pakistan: national guidelines for clinicians. Pak J Neurol Sci 2015; 10(3): 47-62.

17. Poverty and social safety nets. Chapter 15. Pakistan economic survey 2013-14.

18. Saleem F, Hassali MA, Shafie AA. Translation and validation study of morisky medication adherence scale (MMAS): the Urdu version for facilitating person-centered healthcare in Pakistan. Int J Pers Cent Med 2012; 2(3): 384-90.

19. Chinnaiyan S, Narayana S. Adherence to Anti epi-leptic Therapy in Adults. J Neurosci Rural Pract 2017; 8(3): 417-20.

20. Moura LM, Carneiro TS, Cole AJ, Hsu J, Vickrey BG, Hoch DB. Association between addressing antiseizure drug side effects and patient-reported medication adherence in epilepsy. Patient Prefer Adherence 2016; 10(2): 2197-07. 